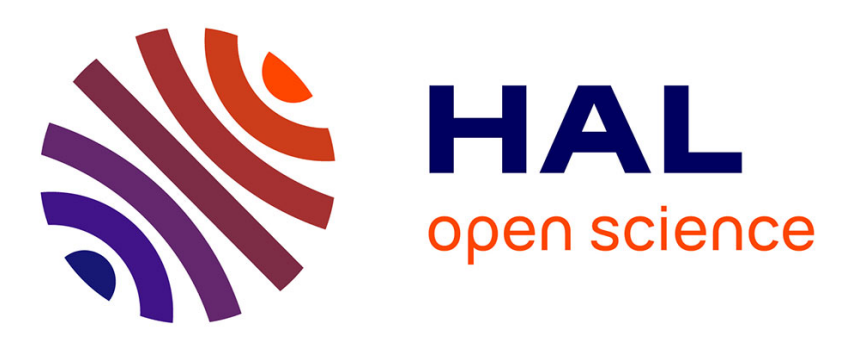

\title{
Mechanochromic LLDPE Films Doped with NIR Reflective Paliogen Black
}

Cosimo Micheletti, Pierpaolo Minei, Marco Carlotti, Virgilio Mattoli, Francesco Muniz- Miranda, Anna Perfetto, Ilaria Ciofini, Carlo Adamo, Giacomo Ruggeri, Andrea Pucci

\section{To cite this version:}

Cosimo Micheletti, Pierpaolo Minei, Marco Carlotti, Virgilio Mattoli, Francesco Muniz- Miranda, et al.. Mechanochromic LLDPE Films Doped with NIR Reflective Paliogen Black. Macromolecular Rapid Communications, 2020, pp.2000426. 10.1002/marc.202000426 . hal-03043710

\author{
HAL Id: hal-03043710 \\ https://hal.science/hal-03043710
}

Submitted on 7 Dec 2020

HAL is a multi-disciplinary open access archive for the deposit and dissemination of scientific research documents, whether they are published or not. The documents may come from teaching and research institutions in France or abroad, or from public or private research centers.
L'archive ouverte pluridisciplinaire HAL, est destinée au dépôt et à la diffusion de documents scientifiques de niveau recherche, publiés ou non, émanant des établissements d'enseignement et de recherche français ou étrangers, des laboratoires publics ou privés. 


\section{Mechanochromic LLDPE Films doped with NIR}

\section{Reflective Paliogen Black}

Cosimo Micheletti, ${ }^{1}$ Pierpaolo Minei,${ }^{1}$ Marco Carlotti, ${ }^{2}$ Virgilio Mattoli, ${ }^{2}$ Francesco MunizMiranda, ${ }^{3}$ Anna Perfetto, ${ }^{3}$ Ilaria Ciofini, ${ }^{3}$ Carlo Adamo, ${ }^{3, *}$ Giacomo Ruggeri, ${ }^{1}$ Andrea Pucci $^{1, *}$

${ }^{1}$ Dipartimento di Chimica e Chimica Industriale, Università di Pisa, Via Giuseppe Moruzzi 13, 56124 Pisa, Italy

${ }^{2}$ Center for Micro-BioRobotics @SSSA Istituto Italiano di Tecnologia Viale Rinaldo Piaggio 34, 56025 Pontedera, Italy

3 PSL University, École nationale supérieure de chimie de Paris, CNRS, Institute of Chemistry for Life and Health Sciences (i-CLeHS), FRE2027, 11, rue Pierre et Marie Curie, F-75005 Paris, France;

Corresponding author:

Prof. Andrea Pucci, Department of Chemistry and Industrial Chemistry, University of Pisa, Via Giuseppe Moruzzi 13, 56124 Pisa, Italy. Email: andrea.pucci@unipi.it

Prof. Carlo Adamo, Institute of Chemistry for Life and Health Sciences (i-CLeHS), FRE2027, 11, rue Pierre et Marie Curie, F-75005 Paris, France. Email: carlo.adamo@chimieparistech.psl.eu 


\begin{abstract}
The perylene bisimide derivative Paliogen Black (P-black) has been proposed as a new chromogenic probe which shows visible (VIS) and near-infrared (NIR) responses after mechanical solicitations of host linear low-density polyethylene (LLDPE) films. P-black has been reported to display strong absorption in the VIS spectrum and unusual reflective and cooling features in the NIR region. Uniaxial deformation of the 2.5, 5 and $10 \mathrm{wt} \% \mathrm{P}$ black/LLDPE films yields a dichroic absorption under polarized light with color variations attributed by the computational analysis to the distinct anisotropic behavior of the transition dipole moments of P-black chromophores. When LLDPE films are deformed, P-black aggregates reduce their size from $\sim 30-40 \mu \mathrm{m}$ to $\sim 5-10 \mu \mathrm{m}$ that, in turn, causes reflectivity losses of about $30-40 \%$ at the maximum elongation. This gives rise to warming of $5-6{ }^{\circ} \mathrm{C}$ of the locally oriented film placed in contact with a black substrate under the illumination with an IR lamp for 5 seconds. These features combined with the high sensitivity of the VIS-NIR response towards mechanical solicitations render P-black as a new solution to detect uniaxial deformations of plastic films through both optical and thermal outputs.
\end{abstract}




\section{Introduction}

Nowadays, smart materials with chromogenic features are widely employed in the detection of external stimuli such as deformation, temperature alterations, and light exposure. ${ }^{[1]}$ Such optical sensors are based on the predictable relationship between the presence of the relevant stimulus and changes in the wavelength of light absorbed and/or emitted by the sensing system. The introduction of chromogenic species into polymers in the form of dispersed or covalently bonded chromophores have been reported as the most exciting and versatile procedure for conferring color features that are strongly depending on the environment variations. ${ }^{[2,3]}$ Moreover, the possible formation of dye aggregates opens a wealth of exciting opportunities for the development of polymers with targeted chromogenic features. Notably, molecular aggregates can display entirely new features with respect to the isolated dye molecules and result extremely sensitive to external solicitations thus supporting smart materials as sensitive optical sensors. ${ }^{[4]}$ Polymers that respond to mechanical stimuli through variations of their optical features are called mechanochromic. Mechanochromism in polymers was reported for the first time by Weder in $2002^{[5]}$ and it has been supported by using diverse polymeric materials and different classes of aggregachromic dyes and fluorophores. ${ }^{[6-11]}$ Notably, the optical responses towards mechanical solicitations are consistent with variations in the absorption and/or emission of these dye/polymer assemblies due to modifications of their interphase interactions and chromophore orientation towards the stress direction. ${ }^{[2,3,7,12,13]}$ Many practical applications can be predicted, e.g. mechano- and pressure sensors, ${ }^{[14,15]}$ indicators of mechano-history, security plastics and papers and data storage devices. ${ }^{[16-20]}$ and new solutions are provided everyday. ${ }^{[21-27]}$ Among the different chromogenic dyes, perylene bis-imide derivatives (PBIs) are one of the most investigated since their optical features result strongly depending on molecular packing among the chromophoric units. $^{[4,28-30]}$ The disaggregation phenomena of PBIs assemblies triggered by 
polymer deformation causes a clear modification of the their optical features with very evident changes especially in emission. ${ }^{[7,31]}$ Dyes embedded into plastic films are also reported to display a well-defined dichroic pattern in polarized light owing to the oriented chromophore assemblies towards the drawing direction of the film. ${ }^{[8,32]}$

Very recently, there has been a growing interest in the application of PBIs as Near-Infrared (NIR) transparent and reflective organic pigments for the development of cool organic coatings for different surfaces. ${ }^{[33-36]}$ Painting building roofs with coatings based on cool pigments, is indeed one of the most accessible solutions to reduce the warming effect caused by the sunlight exposure, which is mainly due to the absorption of the NIR contribution of the solar spectrum. This approach has been recently reported to reduce the energy demand and therefore beneficial for downgrading the urban heat island (UHI) phenomenon. ${ }^{[37]}$ One of the most effective PBIs with NIR reflective features is Paliogen ${ }^{\circledR}$ Black L0086 (P-black, Figure 1 left panel up) that is distributed by BASF as pigment for solar heat management in paints. ${ }^{[38]}$ P-black mimics the transparent and NIR reflective features of certain green plants ${ }^{[39]}$ thanks to the high-symmetry of PBI that favors the formation of crystalline supramolecular assemblies promoted by the intermolecular $\pi-\pi$ interactions among perylene nuclei. ${ }^{[34,36,40-43]}$ Its supramolecular structure preserved within the polymer coatings allowed NIR reflectances close to $50 \%$ and consistent cooling effects. ${ }^{[33,44]}$ Being the NIR reflective features strongly depending on the supramolecular packing, polymer drawing may promote the exfoliation of the dispersed PBIs aggregates, thus causing the loss of NIR reflection that in turn substantially reduces the cooling effect of film surfaces.

In this work, we propose for the first time the use of P-black as a pigment for low-density polyethylene (LLDPE) aimed to endow the derived films with a responsive behavior to mechanical deformations both in the visible and in the NIR region of the spectrum of light. The external stress applied to the LLDPE film is thus detectable as color variations in the 
visible and reflectance reduction in the NIR, this last causing a prompt temperature variation of the film surface under IR irradiation.

\section{Experimental part}

\subsection{Materials}

Paliogen $^{\circledR}$ Black L0086 (P-black) was provided by BASF and used without further purification. Linear low density polyethylene (LLDPE, Dowlex SC 2107, Melt flow index, $190{ }^{\circ} \mathrm{C} / 2.16 \mathrm{~kg} 2.3 \mathrm{~g} / 10 \mathrm{~min}, \mathrm{~d}=0.917 \mathrm{~g} / \mathrm{cm}^{3}$ ) was supplied by Dow Plastics, USA. The remaining chemicals were obtained from Sigma-Aldrich.

\subsection{P-black/LLDPE film preparation}

A desired amount of P-black was dispersed under vigorous stirring in a 5 wt.\% LLDPE solution in toluene at $80{ }^{\circ} \mathrm{C}$. After sonication for $5 \mathrm{~min}$ at $400 \mathrm{~W}$ and $24 \mathrm{kHz}$ with Hielscher's UP $400 \mathrm{~S}$ probe, the solvent was removed by rotary evaporation and the obtained solid blend eventually compression molded at $180{ }^{\circ} \mathrm{C}$ for 5 min into thin film with a thickness between 120 and $150 \mu \mathrm{m}$.

\subsection{Methods}

The thickness of the LLDPE films was measured with a CM1S dial indicator (Borletti, Milan, Italy) with ruby movement bearing. Differential scanning calorimetry (DSC) was performed on LLDPE films under nitrogen atmosphere by using a Mettler Toledo StarE System, equipped with a DSC822c module and following the procedure reported in the literature. ${ }^{[45]}$

Solid-state drawings of the binary films were performed on a thermostatically controlled hot stage at $90{ }^{\circ} \mathrm{C}$. The draw ratio $(D r)$, defined as the ratio between the final and the initial length of the samples, was determined by measuring the displacement of ink-marks printed 
onto the films before stretching. UV-Vis spectra of P-black/LLDPE films were recorded at room temperature over the wavelength range of $350-800 \mathrm{~nm}$ in polarized light with the help of a Perkin-Elmer Lambda 650 equipped with motor-driven Glan-Taylor linear polarizers. UV-Vis-NIR reflectance measurements of P-black/LLDPE films were recorded at room temperature over the wavelength range of $350-2500 \mathrm{~nm}$ by using an Agilent Cary 5000 spectrophotometer equipped with a $150 \mathrm{~mm}$ integration sphere. A commercially available 100W IR lamp (Kerbl, Buchbach, Germany) was used for the heating tests. The Pblack/LLDPE films were placed over the black surface of a Leneta ${ }^{\circledR}$ checkerboard chart and irradiated at a distance of $20 \mathrm{~cm}$ for 5 seconds and the temperature measured by means of a FLIR $^{\text {TM }}$ E6 infrared thermo-camera (FLIR, Wilsonville, OR, USA). The thermal images were opened by the FLIR Tools software (version 2.1) by using the iron palette image setup. The optical microscope analysis was accomplished on a Nikon Eclipse Ni-E equipped with a Thorlab LPVISE200-A polarizer and a Nikon DS Ri2 camera. Particle analysis was performed using the public domain Image J $1.52 \mathrm{k}$ software version image analyzer program developed by the National Institutes of Health (USA) and available on Internet at https://imagej.nih.gov/ij/index.html.

\subsection{Computational details}

P-black molecules have been investigated computationally to analyze and interpret their optical and structural features. We adopted various models to elucidate the available experimental data in both solvent/vacuum medium and in condensed phases.

\subsubsection{Solvent/vacuum calculations}

The molecular structure of P-black molecules has been relaxed in the ground electronic state (GS) using the Gaussian 16 package, ${ }^{[46]}$ adopting the B3LYP exchange and correlation functional $^{[47,48]}$ in conjunction with $6-31+G(d, p)$ basis set and Grimme's D3-BJ dispersion 
correction: ${ }^{[49]}$ this level of theory proved to be suitable in a previous investigation of some of us on a similar system (dye Paliogen Red) ${ }^{[41]}$. All relaxed structures are potential energy minima, as all normal modes have a positive frequency. Calculations of electronic excited states have been performed with the TD-DFT approach using the range-separated exchange and correlation functional CAM-B3LYP ${ }^{[50]}$ to better describe charge-transfer transitions and the spectral shape. Solvent effect was simulated using an implicit solvation model (polarizable continuum model). ${ }^{[51]}$

\subsubsection{Crystal-embedded calculations}

Periodic calculations have been carried out with the Crystal $17^{[52]}$ code at the B3LYP-D3 level with a modified all-electron $6-31+\mathrm{G}(\mathrm{d}, \mathrm{p})$ basis set to match that of non-periodic calculations. Numerical DFT integration has been performed considering 75 radial points and 974 angular points, ensuring an error on the integrated electron density to an accuracy of $10^{-5}$ e per unit cell. The Coulomb and exchange series were truncated with threshold values of $10^{-}$ ${ }^{7}, 10^{-7}, 10^{-7}, 10^{-7}$, and $10^{-21}$. A tolerance of $10^{-7}$ a.u. has been used for the convergence of the self-consistent field procedure. Cell parameters and atomic positions have been let free to relax during structural optimization. Convergence was determined from the root mean square and absolute value of the largest component of the forces and displacements, considering default values $(0.00045$ and 0.00067 au for the forces, and 0.0018 and 0.0027 a.u. for the displacements, respectively). The crystalline structure of P-black belongs to the triclinic P1 space group, with flat perylenetetracarboxylic diimide portions packed in stacks through $\pi-\pi$ interactions, with experimental lattice parameters of $\mathrm{a}=4.09 \AA, \mathrm{b}=9.71 \AA$, and $\mathrm{c}=17.11 \AA$, $\alpha=98.82^{\circ}, \beta=91.07^{\circ}, \gamma=101.58^{\circ} .^{[53]}$ The optimized lattice parameters obtained are $\mathrm{a}=3.99$ $\AA, \mathrm{b}=9.78 \AA, \mathrm{c}=16.96 \AA, \alpha=96.72^{\circ}, \beta=90.04^{\circ}$, and $\gamma=101.67^{\circ}$. In addition, the flat portions of neighboring molecules are found at about $3.49 \AA$ apart, with respect to an 
experimental value of $3.59 \AA$. To create a more cubic-like box, we adopted a $7 \times 3 \times 2$ monoclinic supercell, resulting in a simulation box of volume $\sim 28 \times 29 \times 34 \AA^{3}$.

Starting from the optimized crystal structure obtained, a large supercell was built and partitioned into three zones, according to the SC-Ewald approach. ${ }^{[54]}$ At the inner first zone treated at the QM level, two different clusters with either one, two, or three P-black molecules have been considered. The intermediate second zone consisted of point charges fixed at the value of the Mulliken atomic charges of the periodic calculation, while the point charge values of the outer third zone have been adjusted to impose the exact Madelung potential of the infinite periodic system on the first two zone sites. Further details can be found in ref 51. ${ }^{[55]}$ Vertical TD-DFT calculations with the aforementioned models (embedded monomer and dimer of P-black) have been carried out with Gaussian 16, thus including the effects of the crystal environment. The embedded dimer model was also used to test the dependence of computed spectra on the intermolecular distance and relative translation. All calculations (both embedded and not) have been carried out using the Pople's 6-31+G(d,p) basis set, and dispersion forces were modeled employing Grimme's D3-BJ correction.

\section{Results and discussion}

P-black is an insoluble PBI pigment that was dispersed by ultrasonication in toluene containing the $5 \mathrm{wt} \%$ of linear low-density polyethylene (LLDPE). LLDPE films containing different concentrations $(2.5,5$ and $10 \mathrm{wt} \%)$ of P-black were prepared by compression molding of the respective LLDPE mixtures. The presence of P-black did not substantially altered the thermal properties of LLDPE films, whose crystallinity and melting point were only slightly enhanced at the highest pigment content of $10 \mathrm{wt} \%$ (Table S1). No thermal transitions attributed to P-black were detected up to $300{ }^{\circ} \mathrm{C}$ in agreement with the thermal 
behavior of PBI pigments. ${ }^{[43,56]}$ The UV-Vis spectra P-black/LLDPE films show absorption maxima centered at 430 and $680 \mathrm{~nm}$ (Figure S1a), which correspond to that displayed in toluene dispersion. Those bands progressively widen with concentration until reaching almost a continuous contribution all over the visible spectrum at the highest pigment content of 10 wt\%. Absorbance flattening at the highest P-black content was attributed to saturation phenomena. Moreover, P-black/LLDPE films did not display any emission behavior, thus suggesting the de-excitation pathways was mainly governed by the typical aggregationcaused quenching phenomenon of PBI insoluble pigments. ${ }^{[57]}$

Calculations were employed to investigate the nature of the electronic transitions that originate the P-black color as a function of the local environment (solution, embedded in matrix). To this end, we have simulated P-black molecules in vacuo, in trichlorobenzene (TCB) solvent, and in an electrostatic field that mimic a crystal environment, refer to Computational detail for the technical part. In Figure 1 (left panel) we report the computed shapes of the optical spectra obtained from a two-molecules model. This latter model has been chosen as it is able to describe not only absorption from a single molecule but also to include in the simplest way excitonic effects, if they are present. This two-molecules model has been proven to be relevant in the case of a similar compound (Paliogen Red). ${ }^{[41]}$ Of note the calculations including the electrostatic field of the crystal environment (hereafter referred to as embedded model) are here considered as the simplest model to simulate absorption within the LLDPE matrix since micro-crystalline aggregates are formed in this matrix and the effect of the low polarity polymer matrix on the absorption properties of this micro-crystal is expected to be negligible.

The calculations carried out in gas and solution phases yield very similar spectral shapes, with just a hypsochromic shift observed when going from vacuum to solution. The corresponding transitions have a local character, without any appreciable inter nor intra 
molecular charge-transfer (Figure 1, right panel), as measured also according refined quantum descriptors. ${ }^{[58]}$
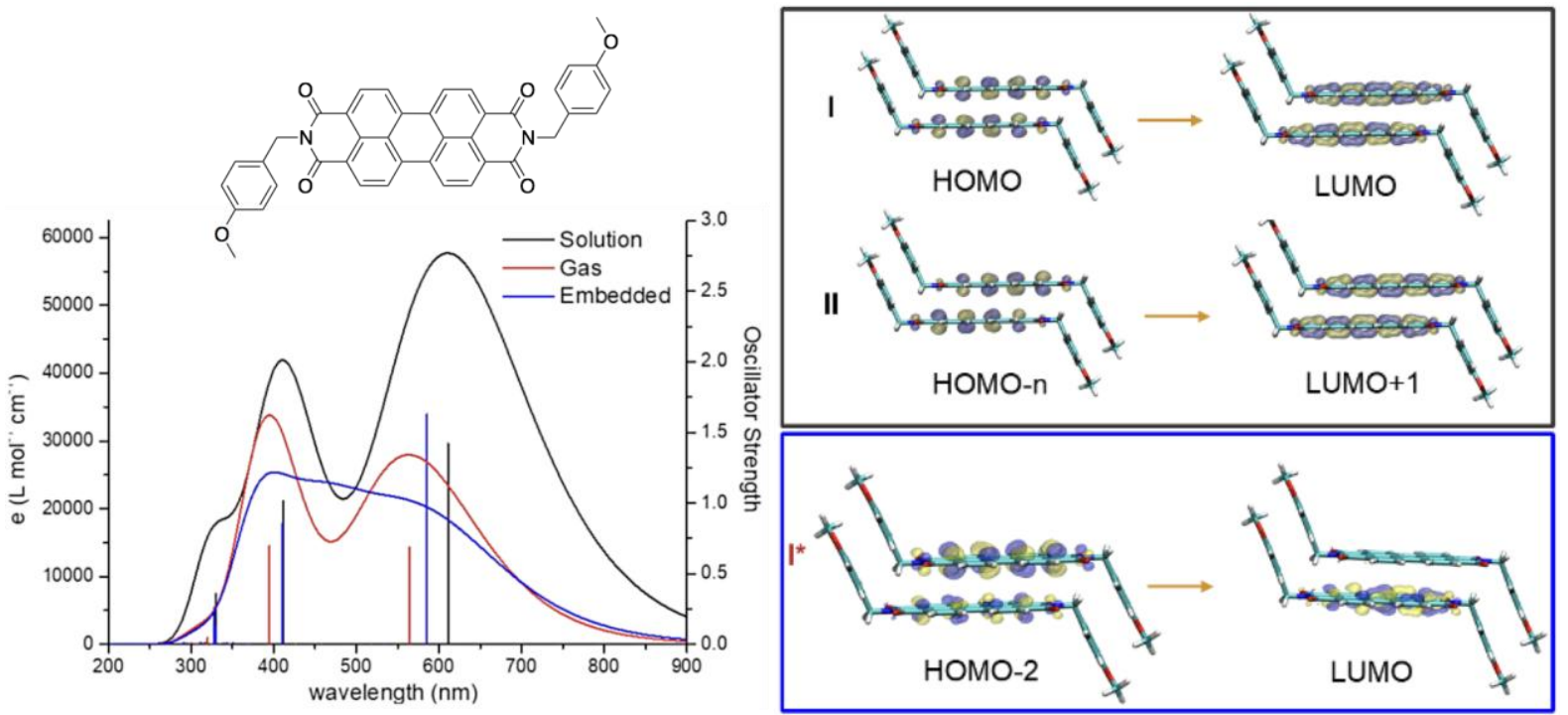

Figure 1. Left panel up: chemical structure of Paliogen ${ }^{\circledR}$ Black L0086 (P-black). Left panel down: computed optical spectra at the TD-CAM-B3LYP level of theory in TCB (black), vacuo (red), and embedded into the crystal field (blue); the curved are smoothed with Lorentzian functions of half width at half height of $0.33 \mathrm{eV}$, while vertical lines are actual vertical $\mathrm{S}_{n} \leftarrow \mathrm{S}_{0}$ transitions. Right panel: main orbitals involved into the first (I) and second (II) calculated band, for the solution/gas calculations (black) and the crystal-embedded one (blue).

Two main peaks can be located, around $\sim 610 \mathrm{~nm}$ and $\sim 410 \mathrm{~nm}$ for the solution phase: these values are within $0.2 \mathrm{eV}$ from the observed peaks in solid phase, in agreement with the accurate level that may be expected from TD-DFT calculations and in agreement with the known tendency of the CAM-B3LYP functional to overestimate excitation energies. ${ }^{[59]} \mathrm{A}$ more detailed analysis of the computational data in vacuum and in solution can be found in the Supporting Information (see Figures S8-S12). The model expected to reproduce the absorption behavior in an aggregate phase, referred to as crystal-embedded and described in the computational details in the crystal embedded calculation section, yields instead a less structured spectrum, with significant absorption in the $300-700 \mathrm{~nm}$ range of wavelengths, thus spanning a large portion of the visible range (as expected from a black material). The 
nature of the first excitation (I* in Figure 1) is also different, with a more pronounced intermolecular charge-transfer character, a behavior found also in the TD-DFT study of so-called Paliogen Red molecule (or Pigment Red 179) ${ }^{[41]}$ when simulated embedded into a crystal. The $\mathrm{D}_{\mathrm{CT}}{ }^{[58]}$ quantum descriptor for charge transfer suggests an hole-electron distance of $\sim 3.15 \AA$, to be compared with an intermolecular distance between P-black molecules in the crystal of $\sim 3.4 \AA$. Models which include just a single P-black molecule or do not take into account the effect of the environment yields a vanishing value for the $\mathrm{D}_{\mathrm{CT}}$ descriptor. A more detailed description of the embedded model can be found in the Supporting Information (see Figures S13-S14 and Table S1-S2).

\subsection{UV-Vis response to mechanical drawing}

The P-black/LLDPE films were then oriented by uniaxial drawing at different draw ratios up to a maximum of 6 (elongation $=500 \%)$. The anisotropic behavior of the stretched films was evaluated by UV-Vis spectroscopy in polarized light (Figure 2), i.e. at different polarization angle with respect to the drawing direction of the film. 

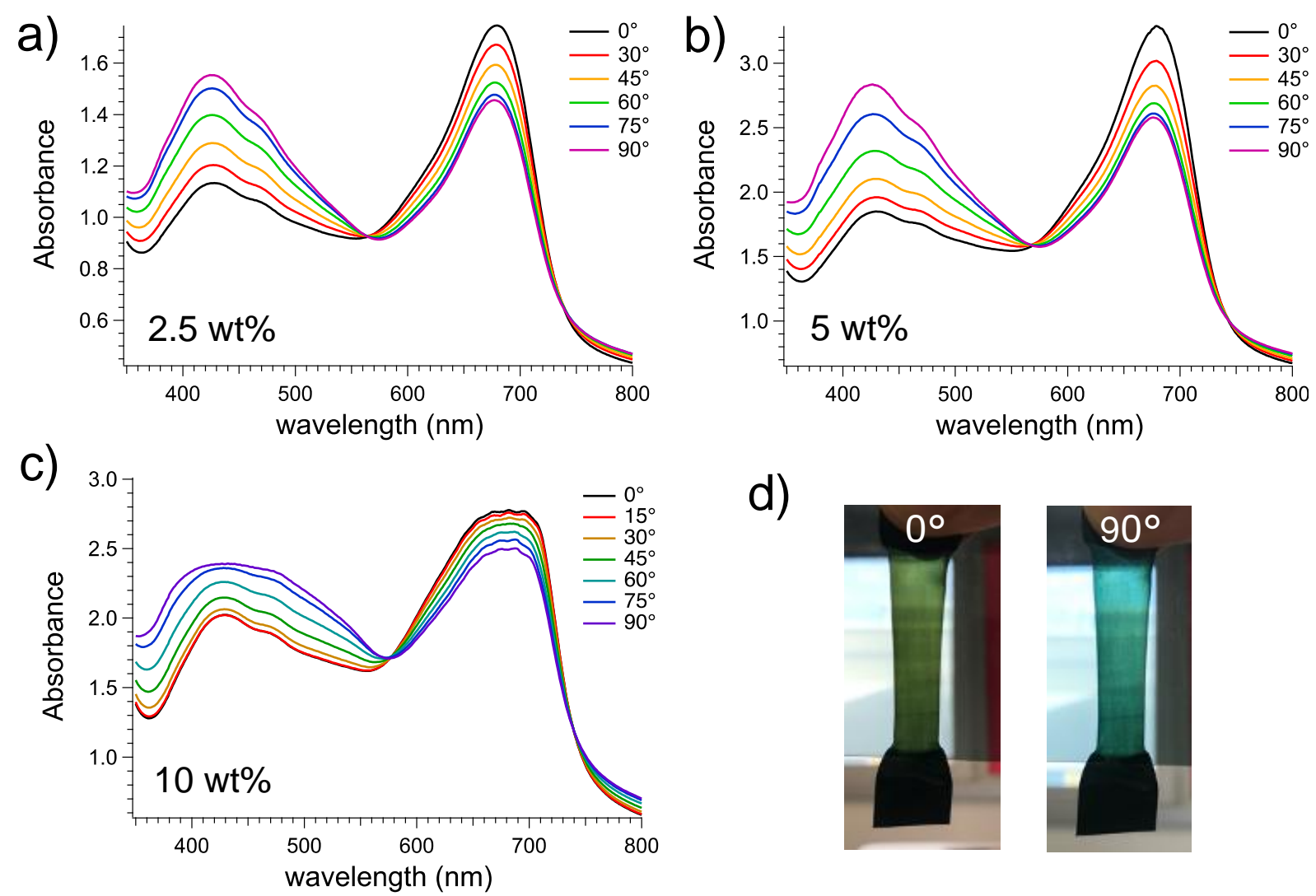

d)
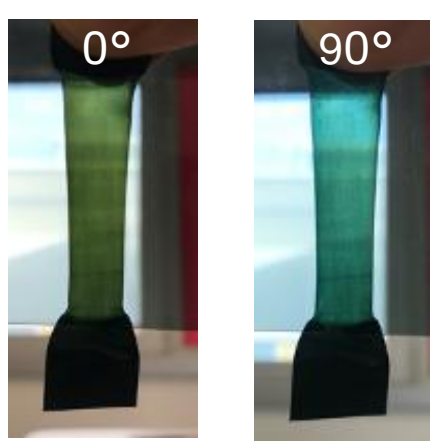

Figure 2. UV-vis absorption spectra as a function of the polarization angle for Pblack/LLDPE oriented films containing a) $2.5 \mathrm{wt} \%$, b) $5 \mathrm{wt} \%$, c) $10 \mathrm{wt} \%$ of pigment; d) photos of the same $5 \mathrm{wt} \%$ P-black/LLDPE oriented film taken by superimposing a linear polarized oriented parallel $\left(0^{\circ}\right)$ and perpendicular $\left(90^{\circ}\right)$ with respect to the drawing direction. $D r=6$ in all cases.

The mechanical drawing of the P-black/LLDPE films conferred to the plastic materials a well-defined dichroic behavior under polarized light. It was worth noting that by varying the direction of the polarization angle with respect to the drawing direction of the films the absorption bands experienced an opposite behavior (Figure 2a-c). Notably, the band at 430 $\mathrm{nm}$ increased its intensity whereas that at longer wavelengths (i.e., $680 \mathrm{~nm}$ ) decreased its contribution, flanked by the existence of a clear isosbestic point at about $570 \mathrm{~nm}$, thus supporting the existence of two different populations of chromophoric assemblies. The behavior was confirmed for all the films investigated, therefore suggesting that dichroic assemblies of pigment molecules were generated also at the highest pigment content of 10 wt $\%$, notwithstanding the reduced absorbance variations caused by possible signal flattening 
due to saturation phenomena (Figure 2c). We did not find such behavior in unstretched samples (Figure S1b), only negligible absorbance variations were detected in polarized light and possibly attributed due to uneven orientation of P-black aggregates during film formation by compression molding.

Notably, the mechanochromic response was clearly visible simply by observing the oriented portions of the LLDPE films under a linear polarizer (Figure 2d). The color changed accordingly to the absorption variations from yellow-green $\left(0^{\circ}\right)$ to dark-cyan $\left(90^{\circ}\right)$.

The effect provided by the P-black content and the draw ratios on the chromogenic behavior was also studied in terms of the absorbance variation $\Delta \mathrm{A}$ (Table 1 and Figure $\mathrm{S} 2$ ). 
Table 1. Absorbance variations at 430 and $680 \mathrm{~nm}$ for P-black/LLDPE films at different pigment content and draw ratio (Dr). $\Delta \mathrm{A}=\mathrm{A}_{90^{\circ}}-\mathrm{A}_{0^{\circ}}$

\begin{tabular}{|c|c|c|c|c|c|c|}
\hline Entry & \multicolumn{2}{|c|}{$\mathrm{Dr}=3$} & \multicolumn{2}{c|}{$\mathrm{Dr}=4$} & \multicolumn{2}{c|}{$\mathrm{Dr}=6$} \\
\hline & $\Delta \mathrm{A}_{430}$ & $\Delta \mathrm{A}_{680}$ & $\Delta \mathrm{A}_{430}$ & $\Delta \mathrm{A}_{680}$ & $\Delta \mathrm{A}_{430}$ & $\Delta \mathrm{A}_{680}$ \\
\hline $\begin{array}{c}2.5 \mathrm{wt} \% \text { P- } \\
\text { black/LLDPE }\end{array}$ & 0.43 & -0.30 & 0.51 & -0.40 & 0.43 & -0.30 \\
\hline $\begin{array}{c}5 \mathrm{wt} \% \text { P- } \\
\text { black/LLDPE }\end{array}$ & 0.20 & -0.18 & 0.63 & -0.41 & 0.78 & -0.45 \\
\hline $\begin{array}{c}10 \mathrm{wt} \% \text { P- } \\
\text { black/LLDPE }\end{array}$ & 0.16 & -0.10 & 0.18 & -0.12 & 0.22 & -0.16 \\
\hline
\end{tabular}

The data reported in Table 1 revealed that the dichroic phenomenon was already obtained at the smallest deformation extent $(\mathrm{Dr}=3)$ and particularly evidenced in the LLDPE films containing the lowest $2.5 \mathrm{wt} \%$ content, i.e. reaching absorbance variations of 0.43 . Pblack/LLDPE films containing the $5 \mathrm{wt} \%$ of the pigment revealed as the most sensitive towards mechanical drawing, with $\Delta \mathrm{A}$ values progressively raising with draw ratio. Notably, a maximum of $\Delta \mathrm{A} \sim 0.8$ was reached at the highest $\mathrm{Dr}=6$. Conversely, LLDPE films containing the 2.5 and $10 \mathrm{wt} \%$ of P-black showed lower sensitivity towards uniaxial drawing with $\Delta \mathrm{A}$ values mostly similar for all the draw ratio investigated. This phenomenon could be possibly attributed for the former to a maximum chromophore orientation already gathered during the early stages of uniaxial deformation and for the latter to the difficulties of orienting the large content of P-black assemblies (i.e., $10 \mathrm{wt} \%$ ) along the drawing direction and confined in the amorphous phase between polymer crystallites even at the highest $\mathrm{Dr}=6$. Nevertheless, absorbance flattening caused by saturation phenomena in LLDPE films containing the $10 \mathrm{wt} . \%$ of P-black cannot be excluded, thus affecting $\Delta \mathrm{A}$ linear variations.

It was worth noting that the absorption band at about $430 \mathrm{~nm}$ appeared more sensitive to uniaxial deformation than that at about $680 \mathrm{~nm}$ for all the P-black/LLDPE films investigated. This behavior was firstly attributed to the absorbance flattening issue, since the absorption band at higher wavelength was also the more intense. Nevertheless, such phenomenon can be 
traced back to the transition dipole moments of the optical excitations. Considering as the simplest model to simulate absorption of P-black within the LLDPE the embedded crystal model, since micro-crystalline aggregates are formed in this matrix and the effect of the low polarity polymer matrix on the absorption properties of this micro-crystal is expected to be negligible, we analyze the transition dipole moments of all the most intense $\mathrm{S}_{n} \leftarrow \mathrm{S}_{0}$ transitions. Here it is worth to recall that even if the computed transitions energies are expected be overestimated (i.e., predicted at shorter wavelengths with respect to what experimentally observed) due to known well documented limitations of the employed level of theory (i.e., the CAM-B3LYP exchange-correlation functional used which overestimates transition energies due to its high content of Hartree-Fock exchange) the nature of the electronic transition is expected to be correctly reproduced. Therefore dipole moments, depending on ground and excited state densities are expected to be qualitatively reliable.

The computed dipole moments show a certain extent of variability as reported in Table S3 of the Supporting Information. In particular, transitions \#11 and \#27 expected to contribute to the higher energy band show significantly different absorptions if oriented differently in a single crystal. In fact, this anisotropy increases when a translation is made along the $\mathrm{x}$-axis (see Tables S3 and S4 of the Supporting Information), suggesting that the second band of the spectrum is more sensible to the orientation with respect to incoming light when subject to a lateral stress, as experimentally observed.

Optical microscopy taken on pristine and oriented P-black/LLDPE films (e.g., those containing the 5 wt\% of P-black, Figure S3) revealed that the mechanical drawing was particularly effective in reducing the size of P-black aggregates from about 30-40 $\mu \mathrm{m}$ to 5-10 $\mu \mathrm{m}$ and in orienting them towards the drawing direction. Notably, microscopy images taken on oriented films at $\mathrm{Dr}=6$ and in polarized light (Figure S4) confirmed the results gathered from UV-Vis spectroscopy (Figure 1). It was worth noting that all the oriented samples 
displayed color variations in absorption as a function of the polarization angle (i.e., $0^{\circ}$ and $90^{\circ}$ ) with P-black 5-10 $\mu$ m-sized aggregates mostly oriented towards the orientation direction of the film. The dichroic behavior appeared more evident for the oriented P-black/LLDPE film containing the 2.5 and $5 \mathrm{wt} \%$ of pigment and in agreement with the data reported in Table 1. The highest P-black content of $10 \mathrm{wt} \%$ strongly affected the light transmission of the film and rendered difficult the determination of the aggregates anisotropy throughout the film sample.

Nevertheless, notwithstanding the high absorption of the films, optical microscopy was effective in revealing the dichroic behavior of P-black/LLDPE films at the early stages of mechanical deformation and containing the highest pigment content (10 wt $\%$ of P-black, Figure S5). Notably, the uniaxial elongation corresponding to $\mathrm{Dr}=1.2$ conferred LLDPE film a chromogenic response in polarized light, thus suggesting that even at very small LLDPE deformations the supramolecular structure of P-black assemblies resulted effectively affected. This result was particularly relevant since it demonstrated the sensitivity of the designed P-black/LLDPE system in providing a prompt mechanochromic response towards uniaxial deformation.

\subsection{NIR response to mechanical drawing}

We then investigated the influence of the P-black content and the polymer uniaxial drawing on the film reflectivity in the visible and NIR region. In agreement with literature data, the reflectance spectra were dependent on the optical features of the P-black chromophoric unit, i.e. a strong absorption in the visible region and maximum reflectivity around $800 \mathrm{~nm}$ flanked by a long tail throughout the NIR region (Figure 3). ${ }^{[34,42]}$ 


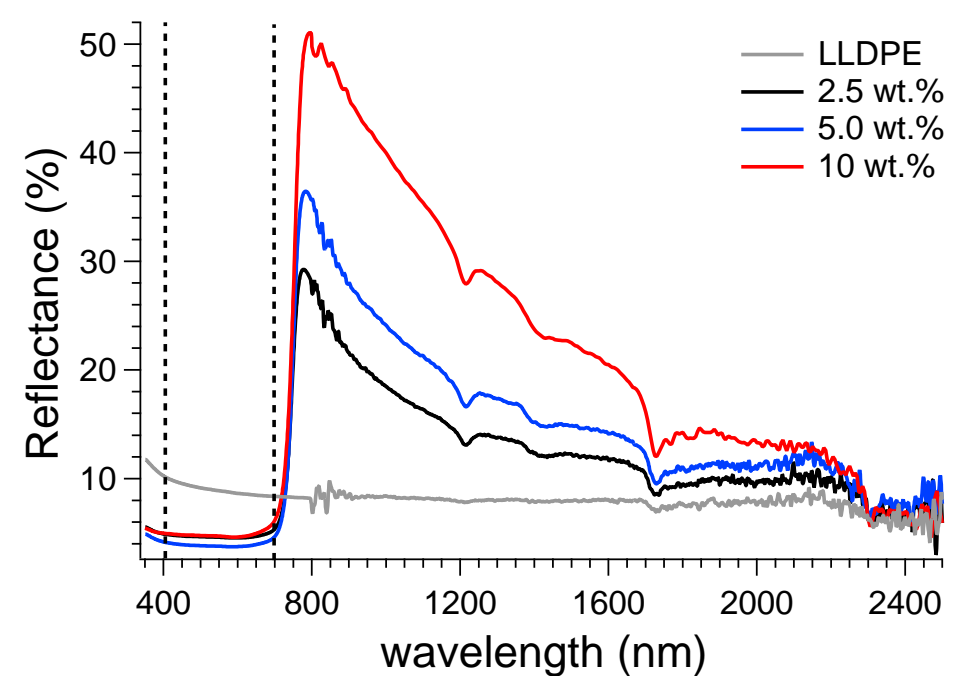

Figure 3. UV-VIS-NIR reflectance spectra of P-black/LLDPE films at different P-black content. The black dashed lines delimit the visible region $(400-700 \mathrm{~nm})$.

Notably, reflectance values progressively raised from $10 \%$ to about $51 \%$ on passing from the neat LLDPE film (gray line) to that doped with the $10 \mathrm{wt} \%$ of pigment (red line) thanks to the NIR reflective features of P-black aggregates. ${ }^{[33,44]}$ NIR reflectances close to $50 \%$ are particularly beneficial for the development of dark organic coatings with cooling characteristics since the affected wavelength region represents about the $25 \%$ of the total solar energy. ${ }^{[36]}$ Visible reflectances of the pigment doped films (i.e., from 400 to $750 \mathrm{~nm}$ ) were lower than that of the neat LLDPE due to the strong absorption of P-black aggregates. 


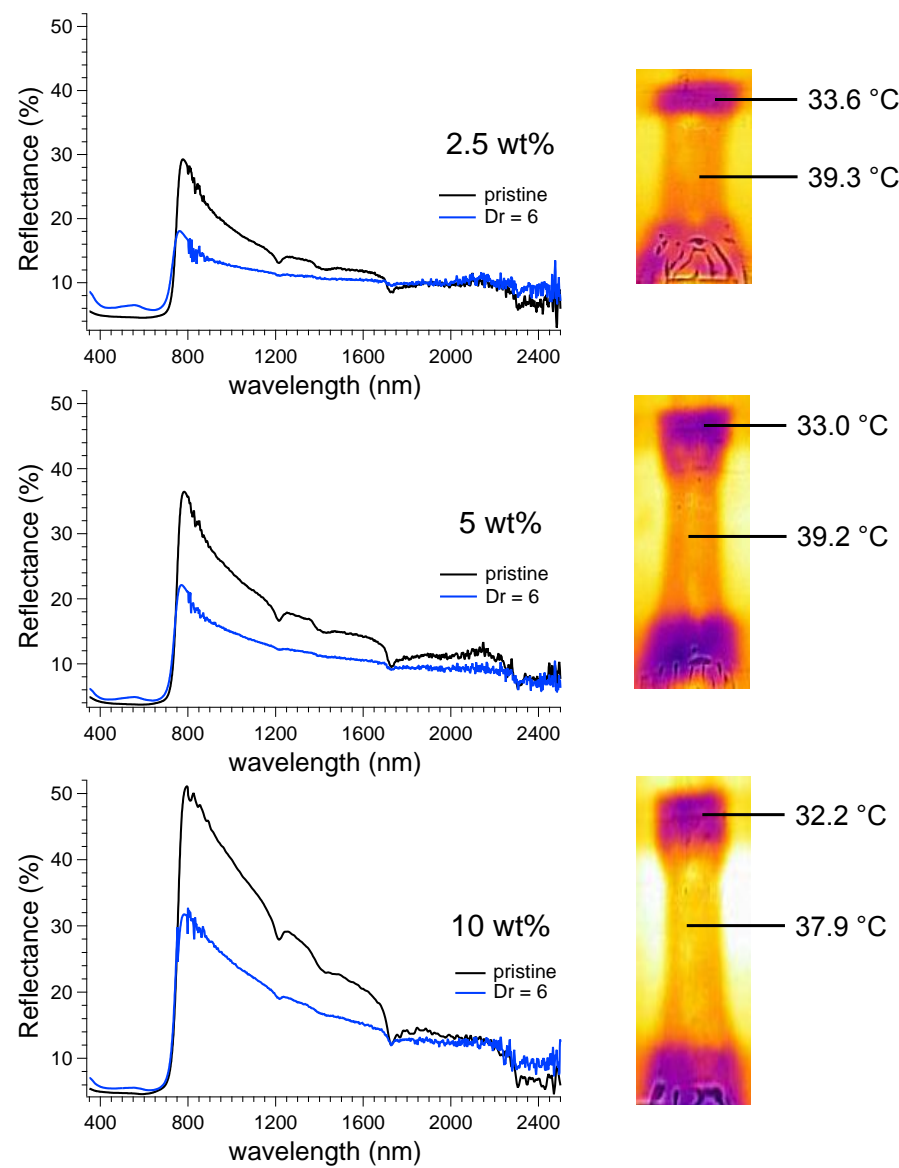

Figure 4. UV-VIS-NIR reflectance spectra of P-black/LLDPE films at different P-black content before (pristine) and after uniaxial deformation at $\mathrm{Dr}=6$. Thermal images of the same films with temperatures recorded for the oriented and unoriented portion of the films after 5 second exposure to an IR lamp (nominal power $100 \mathrm{~W}$, distance from the sample 20 $\mathrm{cm})$

The mechanical drawing of the P-black/LLDPE films $(\mathrm{Dr}=6)$ effectively affected the reflectance of the films with decreasing of about $30-40 \%$ at around $800 \mathrm{~nm}$. This phenomenon might be possibly addressed to a combination of effect: the first resides on the fact that uniaxial drawing caused P-black dilution throughout the oriented film portion; the second consist on the partial exfoliation of the pigment aggregates during deformation as revealed by optical microscopy (Figure S3). The reduction of the average aggregate size of Pblack assemblies has been recently reported to adversely affect pigment reflectivity and, in turn, the pigment cooling characteristics. ${ }^{[44]}$ 
The films were then placed over the black surface of a Leneta ${ }^{\circledR}$ checkerboard chart and irradiated by means of an IR lamp for 5 seconds to investigate the different cooling features of the oriented and pristine portions of the P-black doped LLDPE films. Thermal images taken during lamp irradiation revealed consistent temperature raising of the oriented LLDPE film of about $5-6{ }^{\circ} \mathrm{C}$ and in agreement with reflectance variations. In summary, the addition of P-black endowed LLDPE film with NIR-reflective and cooling characteristics as demonstrated by the progressive temperature reduction from $38.7{ }^{\circ} \mathrm{C}$ to $32.2{ }^{\circ} \mathrm{C}$ on passing from the neat LLDPE film (Figure S6) to that doped with the $10 \mathrm{wt} \%$ of pigment (Figure 4). As soon as the mechanical drawing was applied to the films, reflectance reduction of about 20-30\% caused temperature raising close to $6{ }^{\circ} \mathrm{C}$. Thickness variations occurred during film drawing supposedly contribute to the thermal response specifically for the highly oriented LLDPE samples. Anyway, temperature variations were also detected for the initially oriented $10 \mathrm{wt} \%$ P-black/LLDPE film $(\mathrm{Dr}=1.2)$ with the deformed film portion $4.5{ }^{\circ} \mathrm{C}$ warmer than the pristine counterpart (Figure S7).

\section{Conclusions}

This work enabled the use of P-black as an unique pigment that once embedded into LLDPE films provided combined optical variations in the visible and reflectivity response in the NIR after mechanical uniaxial deformation. Notably, LLDPE films containing the $2.5-10 \mathrm{wt} . \%$ of P-black showed a dichroic absorption profile in linearly polarized light with clear isosbestic points and color variations from yellow-green to dark-cyan. This feature was addressed by density functional theory calculations to the different anisotropic behavior of the transition

dipole moments of the P-black chromophoric assemblies within the oriented LLDPE matrix. Mechanical drawing was also responsible in reducing the average size of P-black aggregates from $\sim 30-40 \mu \mathrm{m}$ in the pristine film to $\sim 5-10 \mu \mathrm{m}$ after maximum film deformation at $\mathrm{Dr}=6$, 
thus also causing substantial reflectivity decrease of $\sim 30-40 \%$ due also to the concomitant Pblack dilution all over the oriented portion of the LLDPE film. Such reflectivity loss was ingeniously exploited since the oriented film in contact with a black substrate displayed a noteworthy warming of 5-6 ${ }^{\circ} \mathrm{C}$ maximum when illuminated with an IR lamp for 5 seconds.

Both optical and thermal outputs revealed very sensitive to mechanical drawing thus opening a new avenue for the direct determination of mechanical deformations of plastic films.

\section{Acknowledgements}

This work was supported by the MIUR-PRIN 20179BJNA2. This project has also received funding from the European Research Council (ERC) under the European Union's Horizon 2020 Research and Innovation Program (grant agreement no. 648558 STRIGES CoG).

\section{References}

[1] P. Bamfield, M. Hutchings, "Chromic Phenomena: Technological Applications of Colour Chemistry, 3rd Edition", Royal Society of Chemistry, 2018, p. 782 pp.

[2] A. Pucci, G. Ruggeri, Journal of Materials Chemistry 2011, 21, 8282.

[3] F. Ciardelli, G. Ruggeri, A. Pucci, Chemical Society Reviews 2013, 42, 857.

[4] F. Würthner, T. E. Kaiser, C. R. Saha-Möller, Angewandte Chemie - International Edition 2011, 50, 3376.

[5] C. Lowe, C. Weder, Advanced Materials 2002, 14, 1625.

[6] A. Pucci, Sensors 2019, 19, 4969.

[7] F. Donati, A. Pucci, C. Cappelli, B. Mennucci, G. Ruggeri, Journal of Physical Chemistry $B$ 2008, 112, 3668 .

[8] G. Prampolini, F. Bellina, M. Biczysko, C. Cappelli, L. Carta, M. Lessi, A. Pucci, G. Ruggeri, V. Barone, Chemistry - A European Journal 2013, 19, 1996.

[9] D. W. R. Balkenende, S. Coulibaly, S. Balog, Y. C. Simon, G. L. Fiore, C. Weder, Journal of the American Chemical Society 2014, 136, 10493.

[10] C. Calvino, E. Henriet, L. F. Muff, S. Schrettl, C. Weder, Macromol. Rapid Commun. 2020, 41, 1900654.

[11] C. Calvino, Y. Sagara, V. Buclin, A. P. Haehnel, A. del Prado, C. Aeby, Y. C. Simon, S. Schrettl, C. Weder, Macromolecular Rapid Communications 2019, 40, 1800705. 
[12] A. Pucci, R. Bizzarri, G. Ruggeri, Soft Matter 2011, 7, 3689.

[13] F. Martini, S. Borsacchi, M. Geppi, G. Ruggeri, A. Pucci, Polymer Chemistry 2014, 5, 828.

[14] M. Zhang, L. Zhao, R. Zhao, Z. Li, Y. Liu, Y. Duan, T. Han, Spectrochim. Acta, Part A 2019, 220, 117125.

[15] R. Zhao, L. Zhao, M. Zhang, Z. Li, Y. Liu, T. Han, Y. Duan, K. Gao, Dyes Pigm. 2019, $167,181$.

[16] M. Karman, E. Verde-Sesto, C. Weder, Y. C. Simon, ACS Macro Lett. 2018, 7, 1099.

[17] C. Calvino, L. Neumann, C. Weder, S. Schrettl, Journal of Polymer Science, Part A: Polymer Chemistry 2017, 55, 640.

[18] G. I. Peterson, M. B. Larsen, M. A. Ganter, D. W. Storti, A. J. Boydston, ACS Applied Materials and Interfaces 2015, 7, 577.

[19] Q. Wang, G. R. Gossweiler, S. L. Craig, X. Zhao, Nature Communications 2014, 5, 4899.

[20] D. R. T. Roberts, S. J. Holder, Journal of Materials Chemistry 2011, 21, 8256.

[21] P. Zhang, X. Shi, A. P. H. J. Schenning, G. Zhou, L. T. de Haan, Advanced Materials Interfaces 2020, 7, 1901878.

[22] K. Suenaga, K. Uemura, K. Tanaka, Y. Chujo, Polymer Chemistry 2020, 11, 1127.

[23] K. Kawasaki, D. Aoki, H. Otsuka, Macromolecular Rapid Communications 2020, 41, 1900460.

[24] C. Calvino, E. Henriet, L. F. Muff, S. Schrettl, C. Weder, Macromolecular Rapid Communications 2020, 41, 1900654.

[25] C. Calvino, Y. Sagara, V. Buclin, A. P. Haehnel, A. del Prado, C. Aeby, Y. C. Simon, S. Schrettl, C. Weder, Macromolecular Rapid Communications 2018, 40, 1800705.

[26] Y. Sagara, M. Karman, E. Verde-Sesto, K. Matsuo, Y. Kim, N. Tamaoki, C. Weder, Journal of the American Chemical Society 2018, 140, 1584.

[27] C. Calvino, A. Guha, C. Weder, S. Schrettl, Advanced Materials 2018, 30, 1704603.

[28] A. Nowak-Król, F. Würthner, Organic Chemistry Frontiers 2019, 6, 1272.

[29] D. Görl, X. Zhang, F. Würthner, Angewandte Chemie - International Edition 2012, 51, 6328.

[30] Z. Chen, A. Lohr, C. R. Saha-Möller, F. Würthner, Chemical Society Reviews 2009, 38, 564.

[31] F. Donati, A. Pucci, G. Ruggeri, Physical Chemistry Chemical Physics 2009, 11, 6276.

[32] A. Pucci, C. Cappelli, S. Bronco, G. Ruggeri, Journal of Physical Chemistry B 2006, $110,3127$.

[33] P. Minei, M. Lessi, L. Contiero, S. Borsacchi, F. Martini, G. Ruggeri, M. Geppi, F. Bellina, A. Pucci, Solar Energy 2020, 198, 689.

[34] M. Mazhar, M. Abdouss, K. Gharanjig, R. Teimuri-Mofrad, M. Zargaran, Journal of Coatings Technology and Research 2017, 14, 207.

[35] J. Qu, Z. N Zhang, W. D Shi, Y. X Zhang, T. Xue, X. Zhang, R. P Zhang, J. Qin, J. Song, Z. Song, W. Zhang, Y. Shi, T. Zhang, X. Xue, R. Zhang, Z. Hongqiang, Z. Zhang, X. $\mathrm{Wu}$, "The Optical Properties of Black Coatings and Their Estimated Cooling Effect and Cooling Energy Savings Potential", 2014, p. 68.

[36] B. Kaur, S. N. Bhattacharya, D. J. Henry, Dyes and Pigments 2013, 99, 502.

[37] A. Muscio, Climate 2018, 6, 12.

[38] BASF, "Paint it cool! Pigments for solar heat management in paints".

[39] H. Akbari, M. Pomerantz, H. Taha, Solar Energy 2001, 70, 295.

[40] F. Mahmoudi Meymand, M. Mazhar, M. Abdouss, J. Coat. Technol. Res. 2019, 16, 439.

[41] F. Muniz-Miranda, P. Minei, L. Contiero, F. Labat, I. Ciofini, C. Adamo, F. Bellina, A. Pucci, ACS Omega 2019, 4, 20315. 
[42] M. Mazhar, M. Abdouss, K. Gharanjig, R. Teimuri-Mofrad, Progress in Organic Coatings 2016, 101, 297.

[43] F. Martini, M. Geppi, G. Barcaro, S. Monti, L. Contiero, G. Ruggeri, M. Lessi, A. Pucci, F. Bellina, S. Borsacchi, The Journal of Physical Chemistry C 2020.

[44] F. Martini, P. Minei, M. Lessi, L. Contiero, S. Borsacchi, G. Ruggeri, M. Geppi, F. Bellina, A. Pucci, Dyes and Pigments 2020, 179, 108401.

[45] M. Carlotti, G. Gullo, A. Battisti, F. Martini, S. Borsacchi, M. Geppi, G. Ruggeri, A. Pucci, Polymer Chemistry 2015, 6, 4003.

[46] M. J. Frisch, G. W. Trucks, H. B. Schlegel, G. E. Scuseria, M. A. Robb, J. R. Cheeseman, G. Scalmani, V. Barone, G. A. Petersson, H. Nakatsuji, X. Li, M. Caricato, A. V. Marenich, J. Bloino, B. G. Janesko, R. Gomperts, B. Mennucci, H. P. Hratchian, J. V. Ortiz, A. F. Izmaylov, J. L. Sonnenberg, Williams, F. Ding, F. Lipparini, F. Egidi, J. Goings, B. Peng, A. Petrone, T. Henderson, D. Ranasinghe, V. G. Zakrzewski, J. Gao, N. Rega, G. Zheng, W. Liang, M. Hada, M. Ehara, K. Toyota, R. Fukuda, J. Hasegawa, M. Ishida, T. Nakajima, Y. Honda, O. Kitao, H. Nakai, T. Vreven, K. Throssell, J. A. Montgomery Jr., J. E. Peralta, F. Ogliaro, M. J. Bearpark, J. J. Heyd, E. N. Brothers, K. N. Kudin, V. N. Staroverov, T. A. Keith, R. Kobayashi, J. Normand, K. Raghavachari, A. P. Rendell, J. C. Burant, S. S. Iyengar, J. Tomasi, M. Cossi, J. M. Millam, M. Klene, C. Adamo, R. Cammi, J. W. Ochterski, R. L. Martin, K. Morokuma, O. Farkas, J. B. Foresman, D. J. Fox, "Gaussian 16", Wallingford, CT, 2016.

[47] C. Lee, W. Yang, R. G. Parr, Physical Review B 1988, 37, 785.

[48] A. D. Becke, The Journal of Chemical Physics 1993, 98, 5648.

[49] S. Grimme, S. Ehrlich, L. Goerigk, Journal of Computational Chemistry 2011, 32, 1456.

[50] T. Yanai, D. P. Tew, N. C. Handy, Chemical Physics Letters 2004, 393, 51.

[51] J. Tomasi, B. Mennucci, R. Cammi, Chemical Reviews 2005, 105, 2999.

[52] R. Dovesi, A. Erba, R. Orlando, C. M. Zicovich-Wilson, B. Civalleri, L. Maschio, M. Rérat, S. Casassa, J. Baima, S. Salustro, B. Kirtman, WIREs Computational Molecular Science 2018, 8, e1360.

[53] M. C. R. Delgado, E.-G. Kim, D. A. d. S. Filho, J.-L. Bredas, Journal of the American Chemical Society 2010, 132, 3375.

[54] M. Klintenberg, S. E. Derenzo, M. J. Weber, Computer Physics Communications 2000, 131,120 .

[55] L. Wilbraham, C. Adamo, F. Labat, I. Ciofini, Journal of Chemical Theory and Computation 2016, 12, 3316.

[56] B. Kaur, N. Quazi, I. Ivanov, S. N. Bhattacharya, Dyes Pigm. 2012, 92, 1108.

[57] J. Mei, N. L. C. Leung, R. T. K. Kwok, J. W. Y. Lam, B. Z. Tang, Chemical Reviews 2015, 115, 11718.

[58] T. Le Bahers, C. Adamo, I. Ciofini, Journal of Chemical Theory and Computation 2011, 7, 2498.

[59] F. Muniz-Miranda, M. C. Menziani, A. Pedone, The Journal of Physical Chemistry C 2014, 118,7532 . 